\title{
Um framework de Computação Orientada a Serviços para sistemas tutores inteligentes baseados em jogos
}

\author{
Patryck Pabllo Borges de Oliveira, MGCTI/UCB, patryckpabllo@yahoo.com.br \\ Edilson Ferneda, MGCTI/UCB, eferneda@pos.ucb.br \\ Hércules A. do Prado, MGCTI/UCB, hercules@ucb.br
}

\begin{abstract}
Resumo. Os jogos digitais do tipo Massively Multiplayer Online Role Playing Game (MMORPG) têm apresentado resultados significativos de aprendizagem quando comparados aos Ambientes Virtuais de Aprendizagem tradicionais. Neste trabalho são exploradas possibilidades de transformar um MMORPG em um ambiente educacional que combina princípios de e-learning e Sistemas Tutores Inteligentes para auxiliar professores a gerenciarem conteúdos educacionais e alunos cooperarem entre si por meio de uma plataforma distribuída. Para isso, é proposto um modelo computacional baseado na Computação Orientada a Serviços para o qual são descritos os principais módulos, serviços, e interfaces, além das interações entre eles.
\end{abstract}

Palavras-chave: sistemas tutores inteligentes; jogos; computação baseada em serviços.

\section{A Service-Oriented Computing framework to game-based intelligent tutoring systems}

\begin{abstract}
The digital games type Massively Multiplayer Online Role Playing Game (MMORPG) have shown significant learning results when compared to traditional Virtual Learning Environments. In this work some possibilities are explored for transforming a MMORPG in an educational environment that combine principles of e-Learning and Intelligent Tutor System. The aiming is to support teachers in managing contents related to education and students to cooperate with each other by means of a distributed platform. For this, a computational model based on Service Oriented Computing is proposed, along with the description of main modules, services, and interfaces, besides the interactions between them.
\end{abstract}

Keywords: intelligent tutoring systems; games; service-based computing.

\section{INTRODUÇÃO}

Sistemas Tutores Inteligentes (STI) fundamentam-se em um modelo de ensino centrado no estudante que busca: (i) raciocinar sobre o processo de aprendizado; (ii) entender suas necessidades individuais; (iii) fornecer representações alternativas de conteúdos; (vi) possibilitar diferentes caminhos de aprendizagem e formas de iteração; além de (v) compreender como a emoção influencia no processo de aprendizagem. Para isso, eles se servem de três modelos relativos: (i) ao domínio do que será ensinado; (ii) ao estudante e (iii) às estratégias pedagógicas relevantes (Woolf, 2009). No entanto, segundo Giraffa (2009), os STI poderiam ser mais efetivos caso eles incorporassem aspectos de ensino supervisionado por professores. Pesquisas recentes sobre STI sugerem que eles incorporem princípios da Educação a Distância (EaD), mais especificamente o ensino via Internet (e-Learning) (Bittencourt, 2009). Esta fusão combinaria características tais 
como o ensino de múltiplos domínios e um suporte colaborativo. Esses ambientes apoiariam estudantes, tutores e professores em atividades de resolução de problemas, acompanhamento de atividades, avaliação, entre outras.

Por outro lado, uma limitação que se observa em softwares educacionais diz respeito ao engajamento dos estudantes. Pesquisas sugerem que quanto maior 0 engajamento dos estudantes, melhor é o aprendizado (Kiili, 2005). Neste contexto, os jogos digitais educacionais apresentam vantagens em relação aos tradicionais softwares educativos, pois neles é possível encontrar elementos importantes que favorecem esse engajamento. Jogos do gênero Massively Multiplayer Online Role Playing Game (MMORPG), em particular, têm recebido especial atenção por apresentarem características consideradas relevantes para um ambiente de aprendizagem, facilitando tanto o aprendizado individual quanto o aprendizado advindo das relações sociais.

Trabalhos anteriores (Oliveira; Ferneda; Prado; Bittencourt, 2013) apresentaram um modelo que orienta a organização do conteúdo pedagógico em projetos STI baseados em de jogos MMORPG. Este trabalho propõe um modelo baseado na Computação Orientada a Serviços (COS) onde são descritos os principais módulos, serviços, e interfaces, além das interações entre eles.

\section{PRINCÍPIOS DO MODELO PROPOSTO}

Advoga-se que uma abordagem que busque fomentar o engajamento dos estudantes passa por uma solução híbrida que considere a interseção entre e-Learning, STI e jogos digitais MMORPG. Essas três áreas são complementares e fornecem princípios para um ambiente de aprendizagem com possibilidades de engajar grupos de estudantes fisicamente distribuídos em atividades de ensino-aprendizagem. Enquanto e-Learning permite ao estudante aprender no momento e local que desejar, os STI contribuem com a adaptação do ensino ao perfil do estudante. Jogos MMORPG levam seus jogadores a pensar, planejar e agir de forma crítica e estratégica, oferecendo características como escolha, controle, colaboração e conquistas, elementos importantes para a aprendizagem baseada na resolução de problemas.

Outras concepções de softwares educacionais também unem alguns desses princípios. A junção entre STI e e-Learning é conhecida como Ambientes de EaD Adaptativos (Bittencourt, 2009). Esses ambientes combinam características tais como: (i) ensino de múltiplos domínios; (ii) o fornecimento de atividades personalizadas tanto para usuários quanto para grupos de usuários; (iii) apoio a estudantes, tutores e professores em atividades de resolução de problemas; (iv) acompanhamento de atividades e; (v) avaliação. Em geral esses ambientes são baseados em interfaces pobres, provendo uma navegação simplista pelo conteúdo, o que os tornam desinteressantes para as novas gerações de estudantes nascidos imersos na cultura digital e interatividade. A junção entre STI e jogos (Maciuszek; Martens, 2011) explora elementos de feedback, motivação, orientação guiada e adaptabilidade, encontrados em jogos com uma perspectiva educacional. Assim como em STI clássicos, essa abordagem considera somente a interação entre um estudante e o sistema, onde o professor não tem papel ativo no processo de ensino-aprendizagem, e sua proposta de ensino é baseada apenas na dimensão do domínio de conhecimento. Esse tipo de jogo não permite também a colaboração do estudante com seus pares. Por fim, diversos trabalhos exploram a junção entre jogos e e-Learning, que pode acontecer em Mundos Virtuais, como o Second Life (Mattar, 2008). 


\section{POSSIBILIDADES EDUCACIONAIS DOS JOGOS DO TIPO MMORPG}

MMORPG é um gênero de jogo digital popular e um dos mais promissores dentro do cenário de estudos dos ambientes de aprendizagem baseados em jogos (Dickey, 2007; Pearce, 2009). É da classe Massive Multiplayer Online Game (MMOG), que se característica por seus jogadores estarem conectados por uma rede local de computadores ou pela Internet e por permitir que seus jogadores criem e interpretem personagens, colaborem, organizem estratégias, planejem e interajam com objetos, recursos e outros jogadores em um mundo virtual dinâmico e persistente.

No mundo de um MMORPG, cada jogador é representado por um personagem virtual (avatar). Tudo o que acontece com o jogador é registrado no servidor em tempo real. Assim, quando ele voltar ao mundo virtual, o seu personagem estará com os mesmos atributos e características de quando o jogador saiu. Quase todos os MMORPG possuem um sistema de progressão do personagem no qual os jogadores ganham pontos de experiência em função da aquisição de novos conhecimentos ou habilidades, e usam essa experiência para que seu personagem evolua no jogo. Os grupos ou clãs são associações de jogadores que escolhem se reunir para conquistar um objetivo em comum. Estes objetivos podem ser sociais, financeiros, ou militares. (Riegle; Matejka, 2006)

Neste sentido, Dickey (2007) considera que jogos MMORPG podem ser de grande relevância em projetos de ambientes virtuais de aprendizagem (AVA), haja vista que esses jogos fornecem um ambiente propício para a resolução de problemas, juntamente com elementos que promovem a motivação intrínseca. É importante reconhecer que os jogos são projetados para divertir, enquanto que os ambientes de aprendizagem são criados para educar. Apesar dessas diferenças, há elementos nos projetos de MMORPG que exigem dos jogadores o ato de pensar, planejar e agir de forma crítica e estratégica. Por exemplo, a criação de personagem e a narrativa estão presentes em diferentes projetos educacionais. Em suma, um ambiente MMORPG oferece características como escolha, controle, colaboração e conquistas, importantes para a aprendizagem baseada na resolução de problemas.

Assim como nas Comunidades de Prática, para Freitas e Griffihs (2008), jogos MMORPG são um meio de engajar grandes grupos de estudantes, tornando possível apoiar objetivos de aprendizagem de forma colaborativa. Diversos jogos MMORPG estão sendo usados em situações de aprendizagem, entre eles: (i) Rocheser Castle, para ensinar a história sobre o castelo de mesmo nome; (ii) Mekong e-Sim, no ensino de geografia e engenharia; (iii) America's Army e Full Spectrum Command, considerados poderosos modelos de comunidades colaborativas que apoiam a resolução de tarefas; (iv) Second Life, ambiente utilizado no ensino de matemática e ciências.

\section{COMPUTAÇÃO ORIENTADA A SERVIÇOS}

O avanço das redes de computadores e, mais especificamente, o surgimento da Internet, mudou a natureza da computação, alterando definitivamente a forma como os sistemas computacionais são concebidos. A criação de softwares hoje preconiza o uso de funcionalidades distribuídas em rede, em oposição à antiga concepção de softwares totalmente independentes e isolados do restante do mundo. Esta mudança trouxe a necessidade de se pensar em termos de módulos distribuídos e com papeis específicos. Neste contexto, a Computação Orientada a Serviços (COS), um paradigma computacional que utiliza serviços como elemento fundamental no desenvolvimento 
rápido de aplicações distribuídas e interoperáveis, tem papel relevante. Assim como a Orientação a Objetos promoveu novas formas de compreensão de software, esse novo paradigma trouxe um conjunto de novos princípios de desenho voltados para a concepção de soluções de softwares distribuídos.

Papazoglou e Heuvel (2007) conceituam serviço como uma entidade de software autônoma, independente de plataforma que pode ser descrita, publicada, descoberta e fracamente acoplada. Serviços expressam seu propósito e capacidades através de um contrato. $\mathrm{O}$ contrato é a interface do serviço que define tipos de dados, sua assinatura, e o que é entrada e o que é saída. Segundo o conceito de acoplamento fraco em SOC, o consumidor não precisa conhecer a estrutura interna do serviço, ele precisa conhecer apenas sua descrição, criando uma dependência mínima entre o consumidor e o serviço.

Huhns e Singh (2005) destacam que as arquiteturas de aplicações segundo a COS são dividas em três papeis: provedor, consumidor e catálogo de serviços. O provedor publica ou divulga seus serviços em um catálogo para que os consumidores possam encontrá-los e utilizá-los. A metáfora dos anúncios de classificados em um catálogo telefônico é um bom exemplo deste processo. Um prestador de serviços anuncia suas habilidades e seu contato na página de classificados do catálogo telefônico, enquanto que um consumidor interessado busca no catálogo por tais habilidades que, quando encontradas, o consumidor entra em contato diretamente com o prestador e solicita a execução do serviço.

Krafzig, Banke e Slama (2004) definem o Enterprise Service Bus (ESB) como um importante elemento que conecta todos os participantes de uma solução baseada em serviços. Os autores comparam o ESB com um barramento de hardware, responsável por integrar diferentes componentes de fornecedores distintos. Para Papazoglou e Heuvel (2007), o ESB, entre outras coisas: (i) promove o acoplamento fraco e decompõem a integração de sistemas em diferentes componentes facilmente gerenciáveis; (ii) é baseado em padrões abertos e orientado a mensagens; (iii) permite a realização, implantação e gestão de soluções baseadas em serviços; (iv) promove a interoperabilidade entre aplicações e outros componentes através de interface e adaptadores baseados em padrões.

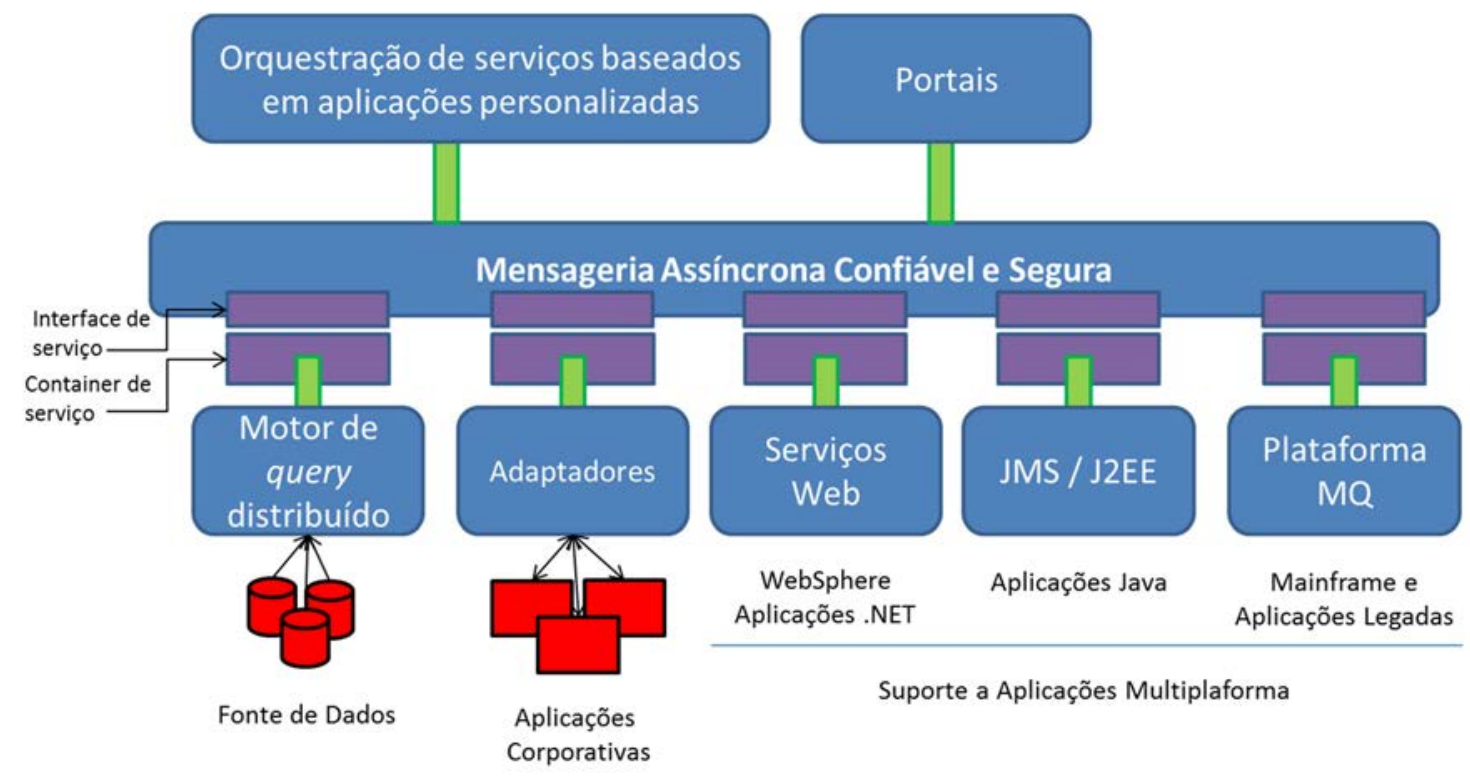

Figura 1: Adaptado de Papazoglou e Heuvel (2007)

Na Figura 1 é apresentado um exemplo de uso do ESB. Nele, são integradas uma aplicação J2EE utilizando JMS, uma aplicação .NET usando um cliente C\#, um 
aplicativo Message Queue que interage com aplicações legadas, bem como aplicações e fontes de dados externos usando Serviços Web. Assim, a função básica de um ESB é agir como mediador. Neste exemplo, a camada de um servidor de portal usa o ESB para interagir com as fontes de dados do back-end.

\section{AMBIENTES VIRTUAIS DE APRENDIZAGEM ORIENTADOS A SERVIÇOS}

Referindo-se ao futuro dos softwares educacionais diante da disseminação dos dispositivos móveis que integram diversas tecnologias, Giraffa (2009) argumenta que a ideia de disponibilização de serviços online apontam para direções promissoras. Nesse sentido, Booth e Clark (2009) veem na COS as bases para a concepção de um ambiente distribuído onde alunos e professores possam plugar seus conteúdos educacionais a um barramento educacional. Os autores apresentam um AVA orientado a serviços com capacidade de plugar dinamicamente ferramentas externas, baseado nos padrões microkernel e ESB. Os professores podem criar ambientes de aprendizagem personalizados, compostos por ferramentas que melhor atendam às suas necessidades. As capacidades de mediação de mensagens do ESB criam um sistema no qual não há uma única interface de usuário. Os usuários serão capazes de escolher a melhor interface para suas necessidades. Segundo os autores, a utilização de uma interface 3D imersiva, por exemplo, é o caminho para criação de uma nova camada de Inteligência Artificial em AVA.

Mircea (2012) identifica na COS o caminho para a integração dos sistemas educacionais novos ou legados que geralmente existem nas instituições de ensino. A autora acredita que o uso da orientação a serviços pode contribuir para a solução de problemas de adaptabilidade, tratamento da complexidade de integração de novos sistemas e ganho de agilidade no desenvolvimento de sistemas, em particular os sistemas distribuídos. Ela chega a propor um roteiro para a construção de AVA orientados a serviços que integrem funcionalidades oriundas de diversas plataformas.

\section{O MODELO PROPOSTO}

O presente trabalho propõe um modelo computacional para a concepção de ambientes interativos de aprendizagem que integra os princípios e-Learning e dos STI aos jogos digitais do tipo MMORPG. Com vistas a conceber um ambiente de aprendizagem que esteja disponível em qualquer lugar e a qualquer momento, com foco no acoplamento fraco entre os sistemas, o modelo proposto foi idealizado na perspectiva de uma arquitetura COS organizada em cinco módulos, conforme apresentado na Figura 2.

O módulo Editor de Missão é uma ferramenta que fornece interface gráfica no qual o professor projeta os recursos a serem utilizados dentro do jogo, por exemplo, os níveis e suas missões. Nele o professor é autor de conteúdo educacional, os recursos são representações dos conteúdos educacionais no jogo. Este módulo usa o Mundo Virtual do Jogo para mediar a persistência dos recursos criados pelo professor. Este módulo pode ter mais de uma instância simultânea. Por exemplo, vários professores podem, ao mesmo tempo, criar recursos educacionais em diferentes instâncias do Editor de Missão.

O módulo Cliente do Jogo gerencia todas as interações do usuário com o Mundo Virtual do Jogo para manter o inventário do estudante. Este módulo apresenta uma interface gráfica onde é apresentado um contexto do modelo de domínio oriundo do STI.

O Motor Educacional corresponde ao modelo clássico de um STI. Ele é 
responsável pelas estratégias educacionais, conforme modelo pedagógico oriundo do STI. Seu objetivo é reagir aos eventos do Mundo Virtual do Jogo, fornecendo, quando solicitado, informações sobre o contexto do estudante. Cabe a este módulo gerir as estratégias educacionais a serem aplicadas aos estudantes inseridos no ambiente do jogo.

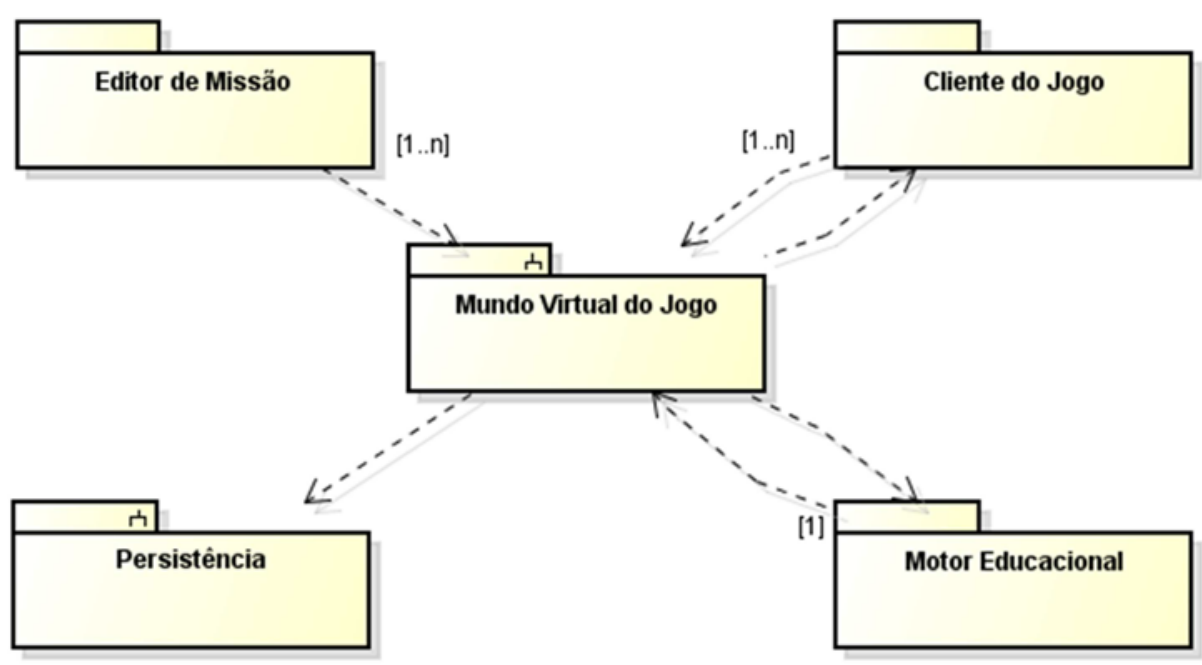

Figura 2 - Visão de Módulos - Os cinco principais módulos do modelo

O módulo Persistência é responsável por manter as informações dos demais módulos do sistema. Nele são armazenados todos os estados do sistema e são mediadas pelo módulo Mundo Virtual do Jogo.

O módulo Mundo Virtual do Jogo é a parte do modelo responsável pelo gerenciamento e execução da plataforma do jogo. É através dele que o estado de cada estudante (o modelo do estudante oriundo do STI) é mantido, ou seja, ele media a comunicação entre os demais módulos.

Na Figura 3 é apresentada a visão de execução de cada módulo do modelo. A figura mostra os principais componentes de cada módulo e as interações. As interfaces dos componentes são abstrações para serviços que, em tempo de implementação, podem ser desenvolvidas como webservices, por exemplo.

O Editor de Missão possui quatro componentes principais: (i) a Interface Gráfica do Usuário (IGU) gerencia a apresentação dos objetos gráficos que formam a interface da aplicação para o usuário, tais como imagens, formulários e textos. Esses objetos refletem visualmente as opções do professor em termos de montagem de grupos/turmas, níveis, missões, recursos de imagem, vídeos e áudios; (ii) o Gerenciador de Editor de Missão (GEM) atua sobre as estruturas de dados relativas à criação, atualização e remoção de missões; (iii) o Gerenciador do Editor de Recursos (GER) atua sobre os recursos a serem utilizados dentro do jogo, como, por exemplo, imagens, vídeos e áudios; (iv) o Gerenciador Administrativo (GA) atua sobre as funcionalidades relativas à administração do sistema, a exemplo do gerenciamento de estudantes, geração de relatórios de acompanhamento dos estudantes e gerenciamento de grupos/turmas.

O componente IGU usa os demais componentes para notificá-los sobre as interações do professor com a interface da aplicação. As notificações da IGU para esses componentes disparam mensagens internas ao Editor de Missão, que manipulará estruturas de dados relativos aos recursos educacionais. Os componentes GEM, GER e GA consomem a interface GerenciadorDeMundoService para executarem operações remotas no módulo Mundo Virtual do Jogo. Isso ocorre, por exemplo, quando o professor publica uma nova missão ou mensagens de texto para os alunos. 


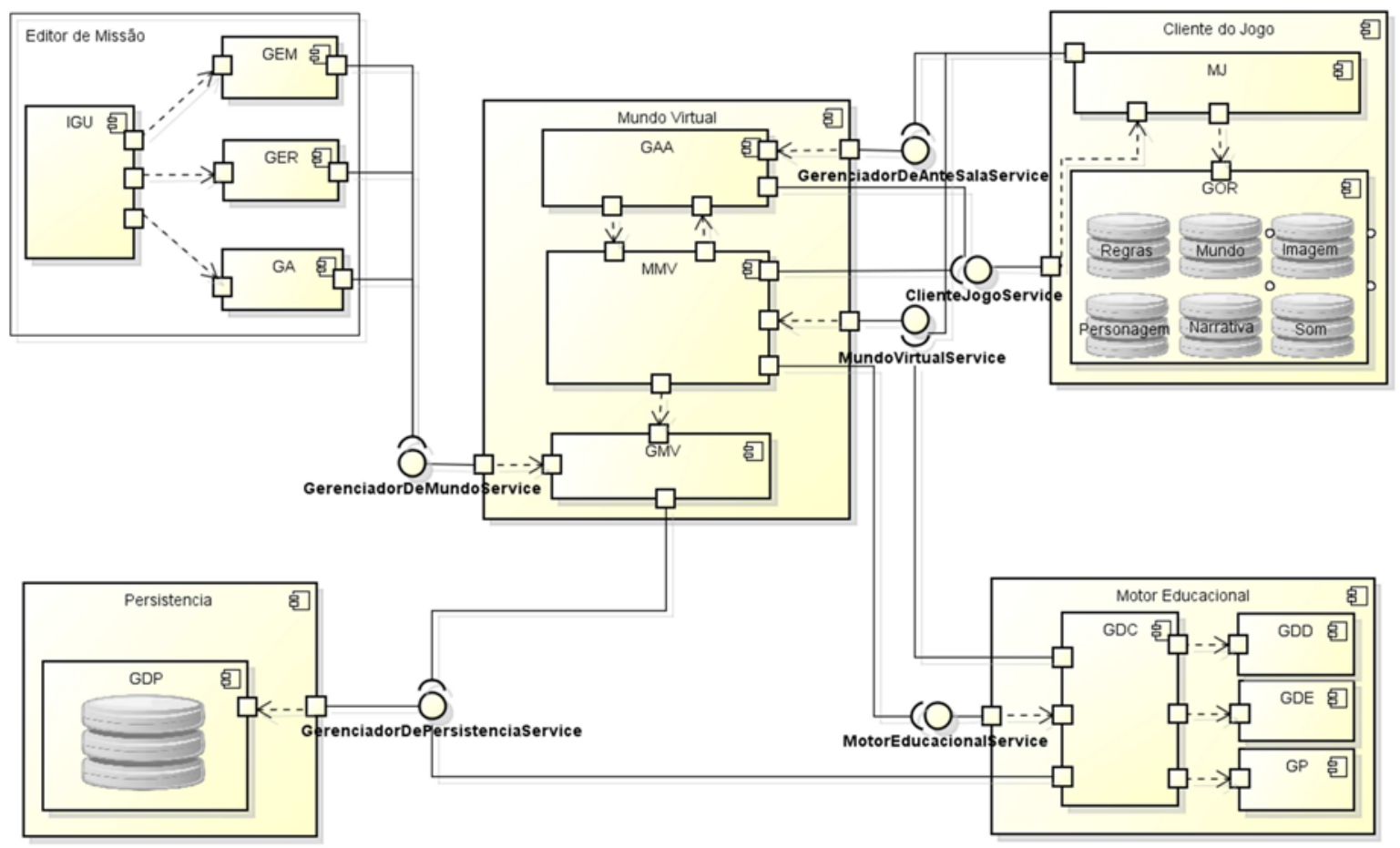

Figura 3 - Visão de execução - componentes e conectores do modelo

O Mundo Virtual do Jogo possui três componentes principais: Gerenciador de Antessala, Motor do Mundo Virtual e Gerenciador de Mundo Virtual. O Gerenciador de Antessala (GAA) cuida do ambiente que antecede as partidas, em que os jogadores recebem instruções sobre suas próximas atividades (missões), podem analisar suas missões anteriores e interagir com outros jogadores com o objetivo de formar grupos, compartilhar experiências e definir estratégias das missões. Este componente troca mensagens com o módulo Cliente do Jogo para manter a interação entre os jogadores presentes. Ele consome a interface ClienteJogoService para executar operações remotas em uma instância de Cliente do Jogo, enquanto o componente Motor do Jogo consome a interface GerenciadorDeAntesalaService para executar operações remotas.

O Motor do Mundo Virtual (MMV) orquestra as interações do jogador com o ambiente virtual. Seu papel é o de traduzir as ontologias do módulo Motor Educacional para o modelo pedagógico próprio do jogo. Por exemplo: (a) uma sequência curricular é mapeada na sequência de missões que o jogador deve cumprir (uma aventura); (b) as orientações são mapeadas para as dicas que o agente animado (agente pedagógico) fornece ao jogador; (c) as atividades são mapeadas nos problemas que o jogador precisa resolver (missões). Assim, em uma situação onde o jogador está resolvendo um problema, suas opções são enviadas na forma de execução de operações remotas para que o módulo Motor Educacional possa agir fornecendo dicas para a resolução do problema. Quando uma missão é completada, uma mensagem é enviada ao Motor Educacional para que ele atualize modelo do estudante (inventário). O MMV tem por objetivo manter a sincronia entre o jogo, o Motor Educacional e as instâncias dos clientes do jogo (avatares) conectados ao sistema. Para isso, este componente consome a interface ClienteJogoService para enviar mensagens ao módulo Cliente do Jogo e consome a interface MotorEducacionalService para enviar mensagens ao módulo Motor Educacional. Enquanto que o módulo Mundo Virtual do Jogo expõe a interface MundoVirtualService para que tanto o Cliente do Jogo quanto o Motor Educacional concretizado por este componente possam enviar mensagens. Os subcomponentes do MMV são: (i) o Gerenciador de Narrativa, responsável pela apresentação e adaptação 
do conteúdo ao jogador; (ii) o Gerenciador de Regras, responsável pelas regras do jogo nas missões; (iii) o Gerenciador de Personagens, que controla os comportamentos dos personagens, e (iv) o Gerenciador de Mundo, que controla o mapa do jogo e os eventos que ocorrem no mundo, coordenando os movimentos do jogador, bem como sua relação com os elementos do ambiente do jogo. O Gerenciador de Mundo Virtual (GMV) recebe mensagens do módulo Editor de Missão e do componente MMV. Sua função é manter o estado de todo o sistema no módulo Persistência, para isso ele consome a interface GerenciadorDePersistenciaService.

O Motor Educacional orquestra o processo de aprendizagem no sistema. Ele reflete o modelo clássico de um STI. Seu objetivo é reagir aos eventos dos componentes GAA e MMV, fornecendo, quando solicitado, informações sobre um estudante/jogador específico, como estrutura curricular, feedback e proposição de missões. Seus componentes são: (i) o Gerenciador de Estudante (GDE), que mantém as informações necessárias para a parametrização do avatar que representará o estudante no mundo virtual, para o acompanhamento e avaliação da evolução de seu conhecimento pelo STI; (ii) o Gerenciador Pedagógico (GP) que, com base no modelo do estudante, fornece o plano de ensino, gerando um currículo adequado ao estudante/jogador. Esse plano inclui estratégias de ensino, fornecendo atividades para resolução de problemas e orientações de como navegar no conteúdo educacional; (iii) o Gerenciador de Domínio (GDD) que, em função desse plano, fornece o conteúdo a ser explorado no âmbito do jogo; (iv) o Gerenciador de Comunicação (GDC) concretiza as operações da interface MotorEducacionalService, mediando o diálogo entre o Mundo Virtual e o Motor Educacional. A interface deste módulo assume o papel de fachada para o componente GDC que fornece a interface entre o usuário e o STI.

Como todo MMORPG, seu ambiente comporta vários jogadores ao mesmo tempo, podendo ser acessado de localizações distintas a qualquer momento. Neste sentido, o módulo Cliente do Jogo pode ser desenvolvido para ser executado em diferentes plataformas, como computador pessoal, tablets, dispositivos móveis. Este módulo tem dois componentes principais: Motor do Jogo (MJ) e o Gerenciador de Ontologias e Regras (GOR). O MJ tem como objetivo coordenar as atividades próprias do jogo, como renderização, física, inteligência artificial, entrada do usuário e etc. Ele executa as regras do jogo baseado nas ontologias geradas pelo MMV. Fazem parte do GOR bases de ontologias com as representações de características e regras do personagem e do mundo do jogo, atualizadas pelo MMV durante a evolução do jogador. Elas contêm, por exemplo: (a) informações sobre o conteúdo de aprendizagem e sobre o personagem; (b) as regras sobre a lógica do mundo virtual; (c) as regras de interações com os objetos estáticos do mundo; $(d)$ as regras de interações com os personagens controlados pelo computador (NPC); (e) as regras de interações com personagens controlados por jogadores humanos; $(f)$ as regras dos desafios, etc. A todo instante um estímulo referente aos movimentos e escolhas do jogador é enviado para o MMV para sincronizar o estado do jogador no Mundo Virtual em relação ao Motor Educacional.

O módulo Persistência pode ser visto como uma abstração de um banco de dados. No entanto, as operações executadas no banco de dados relativas a inserção, atualização e remoção de dados são realizadas por meio das operações disponibilizadas pela interface GerenciadorDePersistenciaService. Seu único componente, o Gerenciador de Persistência (GDP), concretiza as operações descritas na interface GerenciadorDePersistenciaService.

As Figuras 4 e 5 representam duas visões de alocação. A primeira ilustra a distribuição de infraestrutura em uma perspectiva onde os componentes registram seus serviços em um repositório e a segunda ilustra os serviços de mediação ofertados por 
um Barramento de Serviços Educacionais. Os componentes instanciados em suas respectivas máquinas (Cliente do Jogo, Persistência, Mundo Virtual e Motor Educacional) registram seus serviços no Repositório de Serviços. O componente Diretório de Serviços funciona como catálogo de serviços. Nele estão armazenados todos os serviços fornecidos tanto pelos módulos quanto pelo próprio barramento. É o local central onde os consumidores de serviços descobrem os serviços de interesse. A Figura 4 representa dois tipos de serviços: os da camada de aplicação (GerenciadorDeMundoService, MundoVirtualService, GerenciadorDeAnteSalaService, MotorEducacionalService e ClienteJogoService) e um único serviço da camada de infraestrutura (GerenciadorDePersistenciaService). Essa organização dos serviços em aplicação e infraestrutura reflete a arquitetura COS clássica.

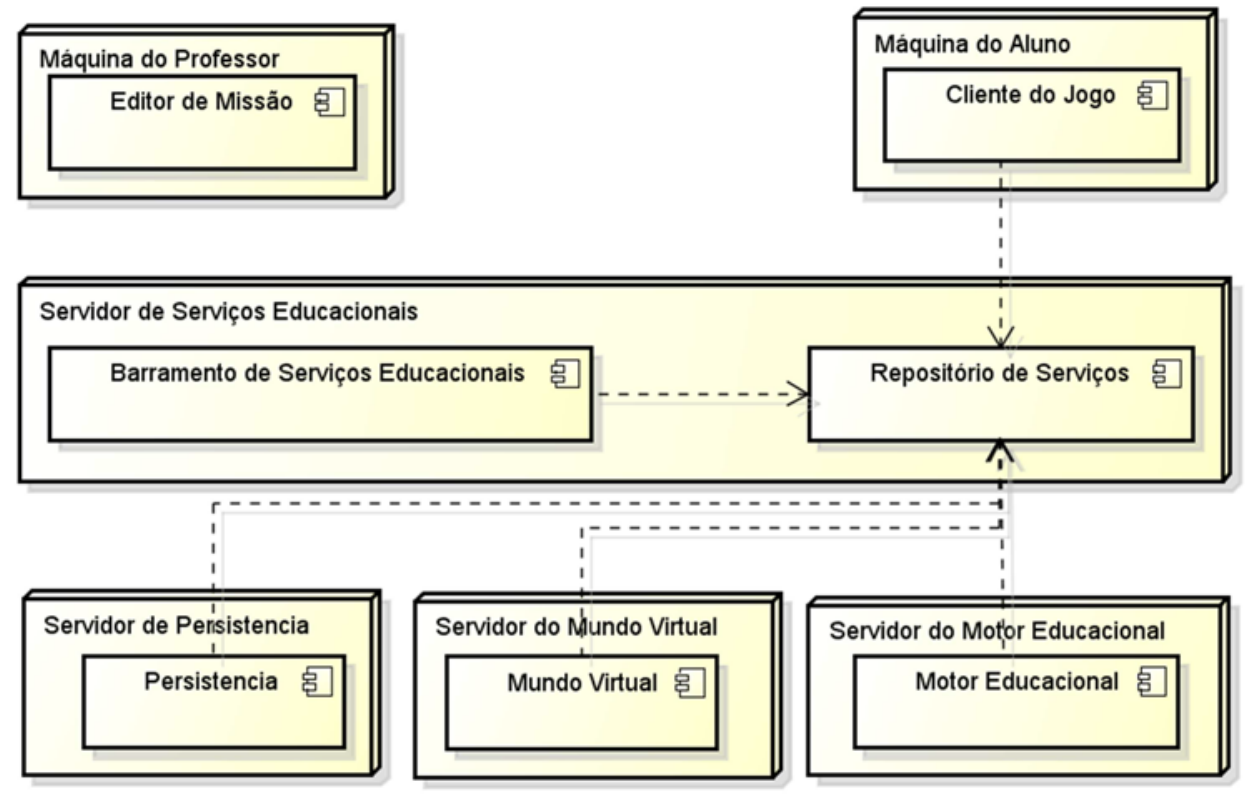

Figura 4 - Distribuição de Infraestrutura e o Registro de Serviços

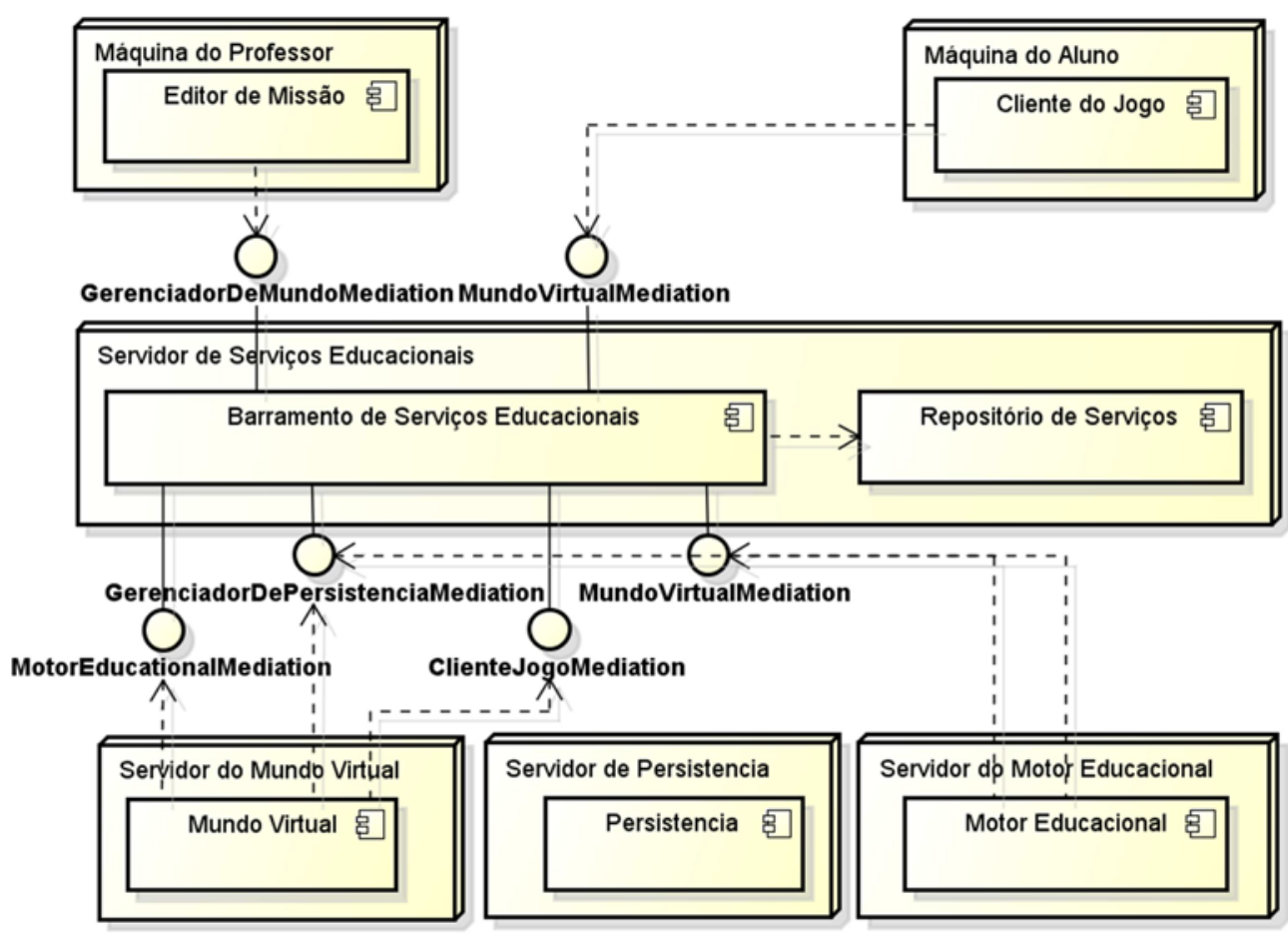

Figura 5 - Distribuição de Infraestrutura e a Mediação de Serviços 
No diagrama apresentado na Figura 5, os componentes (Cliente do Jogo, Persistência, Mundo Virtual, Motor Educacional e Editor de Missão) estão alocados de forma distribuída. Tais componentes consomem e executam serviços de mediação. Esse tipo de serviço é oferecido pelo Barramento de Serviços Educacionais, responsável por integrar e compor serviços de forma inteligente providos pelos módulos participantes do modelo, sincronizando as mudanças de estado entre os módulos conectados ao barramento. O componente Barramento de Serviços Educacionais possibilita a interoperabilidade e o acoplamento fraco entre os módulos. Através dele é orquestrada a conversação de todos os módulos. Por exemplo, quando um usuário inicia uma nova partida, um fluxo hipotético iniciar partida é orquestrado de forma que ele primeiro busque no Motor Educacional as informações do modelo do estudante e do domínio. Em seguida, envia estas informações para o Motor do Mundo Virtual para que ele as incorpore às ontologias próprias do jogo e, por fim, as disponibilize para que o módulo Jogo Cliente (que iniciou a transação) inicie a partida.

\section{CONCLUSÃO}

Este trabalho propõe um modelo de jogo do tipo MMORPG orientado a serviços, combinando princípios de STI com e-Learning. Este modelo baseia-se na composição de módulos para a concepção de um sistema extensível para a integração com módulos adicionais. Busca-se, com este modelo, expandir as possibilidades de abordagens para uma aprendizagem personalizada, permitindo que professores atuem ativamente no processo de ensino-aprendizagem, enquanto que os estudantes possam adquirir conhecimentos advindos da interação social e de forma lúdica.

Como principal contribuição tem-se um modelo que orienta o desenvolvimento de ambientes de aprendizagem orientado a serviços na forma de jogos MMORPG. Arquiteturas na perspectiva COS oferecem vantagens como reusabilidade, escalabilidade, flexibilidade, integração e interoperabilidade. Fornecem também capacidade de mediação de mensagens a partir do ESB, que viabiliza a concretização de seus módulos em diversas plataformas.

Trabalha-se, atualmente, na concepção e desenvolvimento de um jogo baseado no modelo proposto. Isto levará à proposição de um modelo de dados canônico para o intercâmbio de dados entre os módulos/sistemas, além de um refinamento das interfaces dos componentes.

\section{REFERÊNCIAS}

BITTENCOURT, I.I. Modelos e Ferramentas para a Construção de Sistemas Educacionais Adaptativos e Semânticos. Campina Grande: UFCG, 2009. Tese de Doutorado.

BOOTH, A.G.; CLARK, B.P. A service-oriented virtual learning environment. On The Horizon, v.17, n.3, p.232-244. Bingley: Emerald Group Publishing. 2009. Disponível em: <http://www.emeraldinsight.com/doi/abs/10.1108/ 10748120910993268> Acesso em: 12 set. 2014.

DICKEY, M.D. Game design and learning: a conjectural analysis of how massively multiple online role-playing games (MMORPGs) foster intrinsic motivation. Educational Technology Research and Development, v.55, n.3, p.253-273. Springer. Junho 2007. Disponível em: <http://link.springer.com/article/ 10.1007\%2Fs11423-006-9004-7> Acesso em: 14 set. 2014. 
FREITAS, S.; GRIFFITHS, M. Massively Multiplayer Online Role-Play Games for Learning. In: FERDIG, R. E. (Ed). Handbook of Research on Effective Electronic Gaming in Education. Hershey: IGI Global. p. 51-66.

GIRAFFA, L.M.M. Uma odisseia no ciberespaço: O software educacional dos tutoriais aos mundos virtuais. Revista Brasileira de Informática na Educação, v.17, n.1, p.2930. Poro Alegre. 2009. Disponível em: <http://www.br-ie.org/pub/index.php/rbie/ article/view/3/3> Acesso em: 09 set. 2014.

HUHNS, M.N.; SINGH, M.P. Service-Oriented Computing: Key Concepts and Principles. IEEE Internet Computing, v. 9, n.1, p.75-81. Jan/Fev 2005. Disponível em: <http://ieeexplore.ieee.org/xpl/articleDetails.jsp?arnumber=1407782> Acesso em: 03 set. 2014.

KIILI, K. On educational game design: building blocks of flow experience. Tampere: Tampere University of Technology, 2005. Tese de Doutorado

KRAFZIG, D.; BANKE, K.; SLAMA, D. Enterprise SOA: Service-Oriented Architecture Best Practices. Hagerstown: Prentice Hall, 2004.

MACIUSZEK, D.; MARTENS, A. A Reference Architecture for Game-Based Intelligent Tutoring. In: FELICIA, P. (Ed). Handbook of Research on Improving Learning and Motivation through Educational Games: Multidisciplinary Approaches. Hershey: IGI Global. p. 658-682.

MATTAR, J. O uso do second life como ambiente virtual de aprendizagem. Blog Brasileiro Educação a Distância. 2009. Disponível em: <http://www.educacaoadistancia.blog.br/revista/ucp_joaomattar.pdf> Acesso em: 03 set. 2014.

MIRCEA, M. SOA adoption in higher education: a practical guide to service-oriented virtual learning environment. Procedia: Social and Behavioral Sciences, v.31, p.218-223. Elsevier. 2012. Disponível em: <http://www.sciencedirect.com/science/ article/pii/S1877042811029740> Acesso em: 03 set. 2014.

OLIVEIRA, P.P.B.; FERNEDA, E.; PRADO, H.A.; BITTENCOURT, I.I. Integrando sistemas tutores inteligentes a jogos. In: SIMPÓSIO BRASILEIRO DE INFORMÁTICA NA EDUCAÇÃO, 23., 2012. Rio de Janeiro. Anais. Rio de Janeiro: Sociedade Brasileira de Computação. Disponível em: <http://www.brie.org/pub/index.php/sbie/article/view/1730/1491> Acesso em: 167 ago. 2014.

PAPAZOGLOU, M.P.; HEUVEL, W.-J. Service oriented architectures: approaches, technologies. The VLDB Journal, v. 16, p. 389-415. Springer. 2007. Disponível em: $<$ http://link.springer.com/article/10.1007\%2Fs00778-007-0044-3> Acesso em: 12 set. 2014.

PEARCE, C. Communities of Play: Emergent Cultures in Multiplayer Games and Virtual Worlds. Cambridge: MIT Press, 2009.

RIEGLE, R.P.; MATEJKA, W.A. The Learning Guild: MMORPGs as Educational Environments. In: ANNUAL CONFERENCE ON DISTANCE TEACHING AND LEARNING, 22., 2006. Madison. Proceedings. Madison: University of Wisconsin-Madison. Disponível em: <http://www.uwex.edu/disted/conference/ Resource_library/proceedings/06_4095.pdf> Acesso em: 13 ago. 2014.

WOOLF, B.P. Building Intelligent Interactive Tutors: Student-centred strategies for revolutionizing e-learning. Amherst: Elsevier, 2009. 